\title{
Dual left anterior descending artery circulation: a rare anomaly of the coronary arteries
}

\author{
Hashir Kareem, ${ }^{1}$ Tom Devasia, ${ }^{1}$ Rajaram Prasad, ${ }^{1}$ Umesh Pai M ${ }^{2}$
}

${ }^{1}$ Department of Cardiology, Kasturba Medical College, Manipal, Karnataka, India ${ }^{2}$ Department of Cardiology, Manipal College of Allied Health Sciences, Manipal, Karnataka, India

\section{Correspondence to} Dr Hashir Kareem, hashirkareem@gmail.com

Accepted 16 April 2014
CrossMark

To cite: Kareem $\mathrm{H}$, Devasia T, Prasad R, et al. BMJ Case Rep Published online: [please include Day Month Year] doi:10.1136/ bcr-2014-205053

\section{DESCRIPTION}

In normal participants, the left anterior descending (LAD) artery arises from the left coronary artery (LCA) and courses along the anterior interventricular sulcus (AIVS) until it reaches the apex. Dual LAD circulation is an uncommon coronary anomaly in which there are two LAD arteries. A type 4 dual LAD circulation is an extremely rare variant of a dual LAD in which one of the LAD arteries arises from the right coronary artery (RCA).

A 75-year-old man presented to us with angina on exertion of recent onset. The resting ECG was normal and echocardiogram showed normal left ventricular function. He underwent a coronary angiogram which revealed a rare coronary anomaly. There were two LAD arteries. One LAD artery originated from the LCA and coursed along the proximal part of the AIVS and ended well short of the apex ('short LAD') (figures 1 and 2). Another LAD originated from the RCA and coursed along the distal part of the AIVS ('long LAD'; figure 3 and video 1). This pattern was consistent with type 4 dual LAD. The 'short LAD' gave rise to a major septal branch and a diagonal branch. A significant stenotic lesion was noted in the 'short LAD' (figure 2).

Dual LAD is a rare coronary anomaly (with a reported incidence of $1 \%$ ) in which there are two LAD arteries. ${ }^{1}$ One artery travels along the proximal part of the AIVS but stops well short of the

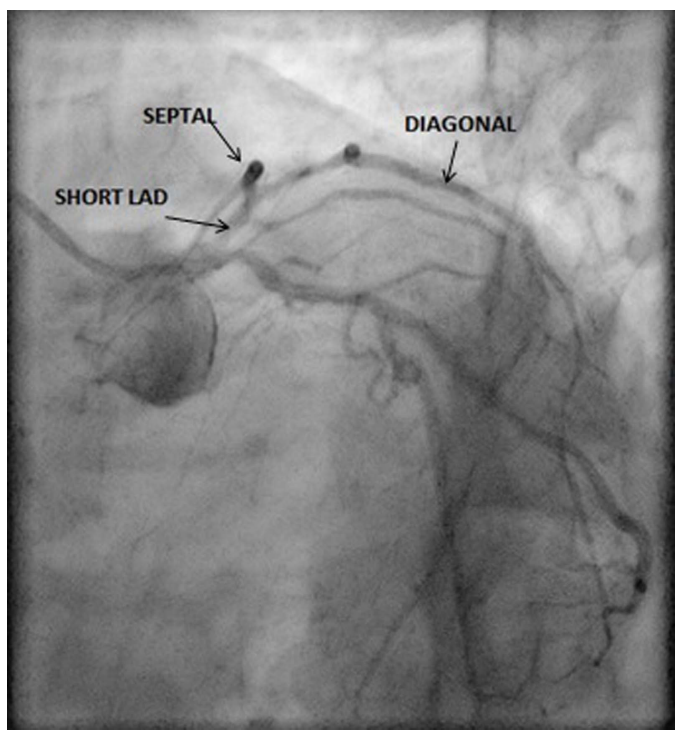

Figure 1 Left anterior oblique caudal view of the left coronary angiogram showing the 'short left anterior descending (LAD)' arising from the left coronary artery. The 'short LAD' gives rise to a septal branch and a diagonal branch.

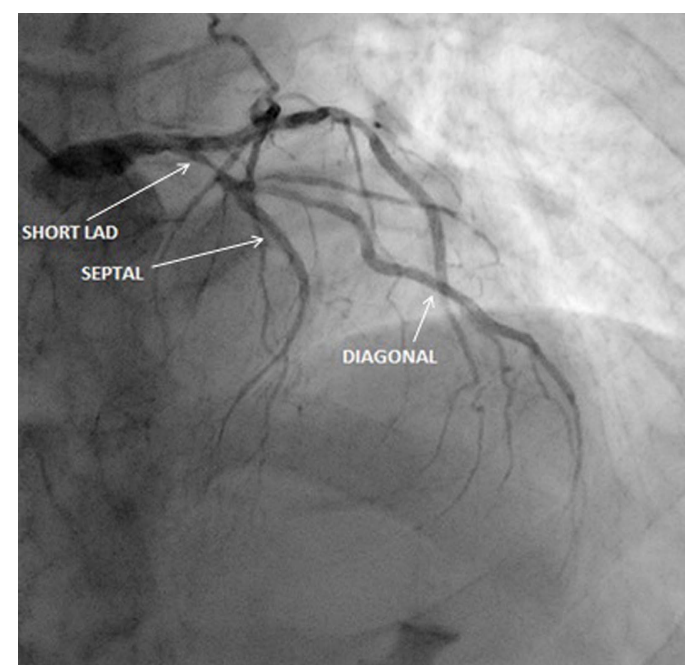

Figure 2 The right anterior oblique cranial view of the left coronary angiogram showing the 'short left anterior descending (LAD)' giving rise to a septal branch and a diagonal branch. The 'short LAD' has an $80 \%$ stenosis.

apex ('short LAD') while the second artery joins the AIVS distally and reaches the apex after originating elsewhere ('long LAD'). ${ }^{1}$ Spindola-Franco et $a l^{1}$ described four types of dual LAD. In the first three types, the 'short' and 'long' LAD arise from the LCA. However, the rarest and most interesting variant is type 4 in which the 'short LAD' arises from the LCA while the 'long LAD' arises from the RCA. ${ }^{1}$ In our case, the patient also had significant

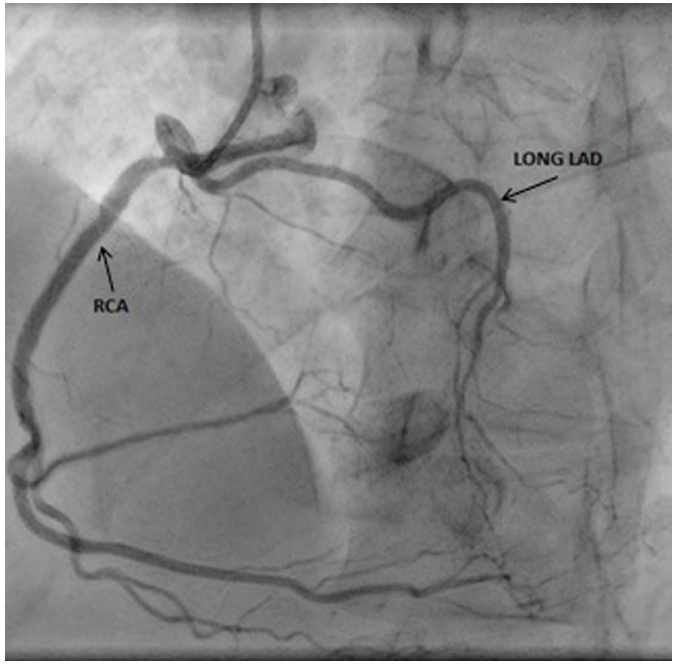

Figure 3 Left anterior oblique cranial view of the right coronary angiogram showing the 'long left anterior descending (LAD)' arising from the right coronary artery (RCA). 


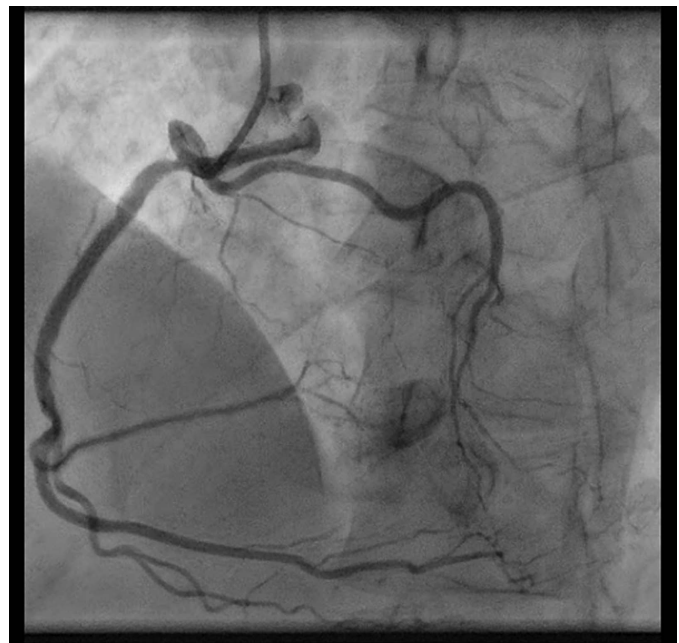

Video 1 LAO cranial view of the right coronary angiogram showing the "long LAD" arising from the Right Coronary Artery (RCA)

stenosis of the short LAD, which was responsible for his symptoms. He was advised to undergo percutaneous coronary angioplasty to the short LAD.

It is important to know about this anomaly since it can potentially present with unusual clinical features and can also lead to confusion on the angiogram where a 'short LAD' may be misdiagnosed as a total occlusion. ${ }^{2}$ Also, the anomaly is of great importance to surgeons while planning coronary artery bypass graft surgery. ${ }^{3}$

\section{Learning points}

- Dual left anterior descending (LAD) is an uncommon coronary anomaly in which there are two LAD arteries.

- In type 4 dual LAD, one of the LAD arteries arises from the right coronary artery and the other from the left coronary artery.

- This unusual anatomical variation can lead to unusual ECG findings and clinical manifestations and is extremely important while planning cardiac surgeries.

Competing interests None.

Patient consent Obtained.

Provenance and peer review Not commissioned; externally peer reviewed.

\section{REFERENCES}

1 Spindola-Franco $\mathrm{H}$, Grose $\mathrm{R}$, Solomon N. Dual left anterior descending artery: angiographic description of important variants and surgical implications. Am Heart J 1983; 105:445-55.

2 Baskan 0, Cengiz E, Yahya P. Dual (type IV) left anterior descending artery. S Afr J Rad 2013;17:145-6.

3 Sajja LR, Shaik MS, Yarigadda RB, et al. Dual left anterior descending coronary artery: surgical revascularization in 4 patients. Tex Heart Inst J 2000;27:292-6.

Copyright 2014 BMJ Publishing Group. All rights reserved. For permission to reuse any of this content visit http://group.bmj.com/group/rights-licensing/permissions.

BMJ Case Report Fellows may re-use this article for personal use and teaching without any further permission.

Become a Fellow of BMJ Case Reports today and you can:

- Submit as many cases as you like

- Enjoy fast sympathetic peer review and rapid publication of accepted articles

- Access all the published articles

- Re-use any of the published material for personal use and teaching without further permission

For information on Institutional Fellowships contact consortiasales@bmjgroup.com

Visit casereports.bmj.com for more articles like this and to become a Fellow 